\title{
Há vida na politica social: representação social de cidadania entre senadores brasileiros
}

I ${ }^{1}$ Carolina Fernandes Pombo-de-Barros, 2 Tatiana Wargas de Faria Baptista,

${ }^{3}$ Ângela Maria Silva Arruda I

Resumo: O artigo debate os resultados de uma pesquisa sobre as representações sociais de cidadania encontradas em discursos emitidos por senadores no plenário do Senado Federal, entre os anos de 2003 e 2006 . O material analisado compreende os discursos de 46 senadores, na temática das políticas sociais, e foi investigado com o uso do programa Alceste. E, apesar de diferentes partidos políticos estarem representados, encontramos relativo consenso em torno da ideia-chave de cidadania. O campo representacional mostrou a centralidade da consciência global e a entrada de temas periféricos nos debates políticos, como a Renda Básica de Cidadania e a Igualdade Racial, assim como sinalizou a pouca influência do setor Saúde nos problemas abordados pelos senadores, no âmbito da política social, no período estudado.

> Palavras-chave: representações sociais; cidadania; Senado; política social.

\author{
1 Psicóloga. Mestre em Ciências \\ pela Escola Nacional de Saúde \\ Pública Sergio Arouca da \\ FIOCRUZ. Endereço eletrônico: \\ carol_pombo@yahoo.com.br \\ 2 Psicóloga. Doutora em Saúde \\ Coletiva pelo IMS-UERJ. \\ Pesquisadora do Departamento \\ de Administração e \\ Planejamento em Saúde da \\ ENSP-FIOCRUZ. Endereço \\ eletrônico: twargas@ensp. \\ fiocruz.br \\ ${ }^{3}$ Psicóloga. Pós-doutora em \\ Psicologia Social pelo ISCTE, \\ Lisboa. Professora adjunta \\ do Instituto de Psicologia da \\ Universidade Federal do Rio de \\ Janeiro. Endereço eletrônico: \\ arrudaa@centroin.com.br
}

Recebido em: 18/05/2012 Aprovado em: 21/11/2012 


\section{Introdução: para compreender a vida das políticas}

Este texto discute a representação social de cidadania nos discursos de senadores brasileiros, no âmbito da política social, durante os anos 2003 a 2006. Buscar as representaçôes sociais de senadores em debates públicos significa analisar a "vida" das políticas, que se expressa nos discursos e explicita interesses, perspectivas e ideias produzidas coletivamente em processos históricos. Significa também procurar alternativas que superem o potencial de explicação das regras institucionais, ainda que as considerando fundamentais. A seguinte afirmação de Draibe (2001) ilustra nosso argumento:

As políticas e os programas também têm, em contrapartida, carne e osso, melhor, têm corpo e alma. São decididas e elaboradas por pessoas, são dirigidas às pessoas ou ao seu habitat, são gerenciadas e implementadas por pessoas. Ora, as pessoas ou os grupos de pessoas que animam as políticas, fazem-no segundo seus valores, seus interesses, suas opções, suas perspectivas, que não são consensuais, nem muito menos unânimes, como sabemos. (DRAIBE, 2001, p. 26).

As representações sociais são, basicamente, hipóteses explicativas compartihadas pelos grupos, sobre objetos socialmente relevantes, que possuem uma dinâmica própria de constituição, permanência e mudança que exigem certo tipo de funcionamento cognitivo, e por outro lado são fundamentais na formação e manutenção do coletivo (MOSCOVICI, 2003). A teoria de Moscovici (1978) tem a capacidade de analisar as interfaces das estruturas macrossociais com os elementos relacionais do cotidiano, da subjetividade com a realidade social, da psicologia com a sociologia, por inserir-se na perspectiva da construção social da realidade (BERGER; LUCKMANN, 1996). O desenvolvimento recente, no Brasil, da temática sobre esfera pública, política, identidade nacional e cidadania, em pesquisas de representaçôes sociais, tem mostrado que esta teoria se articula muito bem com análises sobre a "vida" dos processos políticos (VELOSO, 2006; ARRUDA, 2002; FERNANDEZ et al., 2003; JOVCHELOVITCH, 2000; GOULART, 1992).

Este estudo optou por concentrar-se no papel das ideias no âmbito do Legislativo - enfoque pouco produzido (HOCHMAN et al., 2007). O foco no conhecimento usado e construído pelos parlamentares pode contribuir muito para a compreensão das peculiaridades e transformações das instituiçõos 
políticas do Brasil, que afetam diretamente a noção de cidadania subjacente a nossas políticas, em especial da política de saúde, visto ser esta uma área que preconiza a consolidação de um sistema pautado em princípios universalistas e de justiça social.

O texto aborda desde os aspectos metodológicos até a discussão dos principais resultados. A riqueza do material e do método de análise empregado permitiu discutir aspectos relevantes de nosso sistema político, da proteção social e da saúde pública. Assim, abordamos os temas que aparecem no campo representacional encontrado, como a renda básica de cidadania, a solidariedade e a desigualdade social, e a relação entre cidadania, saúde e mudança nas representações.

\section{Aspectos metodológicos}

O estudo se desenvolveu em três etapas: a) fundamentação teórica, com a discussão das relaçõos entre esfera pública, discurso político e representações sociais; b) análise do contexto de atuação dos senadores, que considerou: a imagem do Congresso Nacional na mídia, as características do sistema político brasileiro e a construção do sistema de proteção, relacionando-o às ideias de cidadania encontradas na literatura; c) pesquisa empírica dos discursos de senadores nos anos de 2003 a 2006.

Os dados empíricos analisados nesta pesquisa são oriundos de discursos proferidos nas sessões do plenário do Senado nos anos de 2003 a 2006. ${ }^{1}$ Os discursos foram extraídos de uma pesquisa na base do Congresso Nacional, o Sistema de Informação do Congresso Nacional (SICON), na qual os filtros utilizados foram as palavras "cidadania" e "política social", no campo "assunto". Como resultado inicial, foram obtidos 126 discursos. Após a leitura dos mesmos, foram excluídos os discursos proferidos por pessoas externas ao Senado e alguns outros que não tinham como tema alguma política ou problema social. Além disso, os apartes que tratavam do tema foram transformados cada um em discursos próprios referentes a seus autores. Ao final, reuniu-se para análise um total de 128 discursos, proferidos por 46 senadores.

A escolha do período a ser pesquisado deveu-se a ser, na época da pesquisa, o período de uma legislatura completa e o último mandato presidencial cumprido, o que possibilitou analisar as representaçôes sociais que estavam ligadas aos 
discursos mais recentes sobre o tema, no âmbito de um sistema político em que o Poder Executivo exerce clara preponderância sobre o Legislativo. Além disso, este foi o primeiro mandato do presidente Lula, eleito por um partido de esquerda, e que teve uma proposta de programa social, o Fome Zero, como carro-chefe de sua campanha eleitoral. Tal fato nos sugeriu que as mudanças ocorridas na coligação do governo intensificariam o debate em torno das políticas sociais. ${ }^{2}$

A opção pelo Senado se deu pela representatividade política e social dessa casa, que, além de representante dos estados no Congresso, possui funções próprias referentes à fiscalização e acompanhamento das atividades do Poder Executivo (BRASIL, 1988). No sistema brasileiro, os senadores exercem papéis estratégicos na formação de coligações, comissões e blocos políticos, num formato típico de presidencialismo de coalizão (ABRANCHES, 1998).

Para uma análise mais detalhada dos parlamentares, foi feita uma categorização com as seguintes variáveis: partido político, quantidade de discursos, unidade federativa, se exerce posição de liderança, oposição, bloco ou partido, se é senador titular ou suplente, se tem projetos de lei na área social ou na área da saúde, e se tem lei aprovada em alguma dessas áreas. O quadro 1, mais adiante, apresenta essa categorização.

Uma análise estatística foi efetuada com o programa de análise textual Alceste. Ele é um método informatizado criado por Marx Reinet em 1986 e que tem sido muito utilizado em pesquisas de representações sociais, porque seus pressupostos teóricos têm afinidade com os princípios epistemológicos da Teoria das Representações Sociais (ALBA, 2004). As palavras são agrupadas por léxicos (seus radicais ou formas reduzidas) e o texto é organizado em recortes do mesmo tamanho (chamados unidades de contexto elementares ou u.c.e.s). A análise resulta em classes de u.c.e.s (classes temáticas), criadas pelas interrelações das formas reduzidas. A Classificação Hierárquica Descendente (CHD) ilustra a pertinência de cada léxico à sua classe e a relação das classes entre si, como pode ser observado na figura 1 . 


\begin{tabular}{|c|c|c|c|c|c|c|c|}
\hline SENADOR & PARTIDO & QTDE & UF & LIDERANÇA & TITULAR/SUPL & PROJETO & LEI \\
\hline Aloisio Mercadante & PT & 3 & SP & g & $\mathrm{s}$ & 3 & 4 \\
\hline Alvaro Dias & PSDB & 1 & PR & $b$ & $\mathbf{s}$ & 1 & 4 \\
\hline Amir Lando & PMDB & 1 & RO & n & $\mathrm{s}$ & 1 & 4 \\
\hline Ana Júlia Carepa & PT & 1 & PA & n & $\mathrm{s}$ & 3 & 4 \\
\hline Antero Paes de Barros & PSDB & 2 & MT & n & $\mathrm{s}$ & 4 & 4 \\
\hline Antonio Carlos Magalhães & PFL & 1 & BA & n & s & 1 & 4 \\
\hline Antonio Carlos Valadares & PSB & 3 & SE & $p$ & $\mathrm{~s}$ & 3 & 4 \\
\hline Arthur Virgilio & PSDB & 1 & AM & $p$ & s & 3 & 4 \\
\hline Augusto Botelho & PDT & 1 & RR & $n$ & $\mathrm{~s}$ & 3 & 4 \\
\hline Cristovam Buarque & PT/PDT & 4 & DF & $n$ & s & 3 & 4 \\
\hline Eduardo Azeredo & PSDB & 3 & MG & n & s & 3 & 4 \\
\hline Eduardo Siqueira Campos & PSDB & 3 & TO & n & s & 1 & 4 \\
\hline Eduardo Suplicy & PT & 17 & SP & $p$ & s & 3 & 3 \\
\hline Eurípedes Camargo & PT & 1 & DF & $n$ & $n$ & 1 & 4 \\
\hline Fátima Cleide & PT & 3 & $\mathrm{RO}$ & n & s & 3 & 4 \\
\hline Flávio Arns & PT & 5 & PR & n & s & 3 & 4 \\
\hline Flexa Ribeiro & PSDB & 3 & PA & $n$ & n & 3 & 4 \\
\hline Garibaldi Alves Filho & PMDB & 1 & RN & n & s & 1 & 4 \\
\hline Geraldo Mesquita Júnior & PSB & 1 & $A C$ & n & s & 1 & 4 \\
\hline Heloísa Helena & PSOL & 3 & $\mathrm{AL}$ & $p$ & s & 3 & 4 \\
\hline Ideli Salvati & PT & 1 & SC & $\mathrm{b}$ & s & 3 & 2 \\
\hline Iris de Araújo & PMDB & 2 & $\mathrm{GO}$ & n & $n$ & 3 & 4 \\
\hline José Jorge & PFL & 2 & $\mathrm{PE}$ & $\mathrm{b}$ & s & 3 & 4 \\
\hline Leomar Quintanilha & PMDB/PCdoB & 2 & TO & $p$ & S & 1 & 4 \\
\hline Leonel Pavan & PSDB & 2 & SC & $n$ & s & 1 & 4 \\
\hline Lucia Vania & PSDB & 4 & GO & n & s & 3 & 4 \\
\hline Luis Otavio & PMDB & 1 & PA & n & s & 3 & 4 \\
\hline Mão Santa & PMDB & 1 & $\mathrm{PI}$ & n & s & 4 & 4 \\
\hline Marcelo Crivela & $\mathrm{PL}$ & 2 & RJ & $p$ & $\mathrm{~s}$ & 3 & 4 \\
\hline Mozarildo Cavalcanti & PPS & 5 & RR & $p$ & $n$ & 2 & 4 \\
\hline Osmar Dias & PDT & 2 & PR & $p$ & $\mathrm{~s}$ & 3 & 4 \\
\hline Papaléo Paes & PMDB & 2 & $\mathrm{AP}$ & n & s & 3 & 4 \\
\hline Patricia Saboya & PPS & 1 & $\mathrm{CE}$ & n & $\mathrm{s}$ & 3 & 4 \\
\hline Paulo Octavio & PFL & 7 & DF & $p$ & s & 1 & 4 \\
\hline Paulo Paim & PT & 11 & PR & n & $\mathrm{s}$ & 3 & 3 \\
\hline Pedro Simon & PMDB & 1 & RS & n & $\mathrm{s}$ & 3 & 4 \\
\hline Ramez Tebet & PMDB & 4 & MS & n & s & 4 & 4 \\
\hline Renan Calheiros & PMDB & 3 & $\mathrm{AL}$ & $p$ & s & 1 & 4 \\
\hline Roberto Saturnino & PT & 1 & RJ & $n$ & $\mathrm{~s}$ & 1 & 4 \\
\hline Romero Jucá & PMDB & 7 & RR & g & s & 1 & 4 \\
\hline Sérgio Zambiasi & PTB & 1 & RS & n & $\mathrm{s}$ & 3 & 4 \\
\hline Serys Slhessarenko & PT & 2 & MT & $n$ & $\mathrm{~s}$ & 3 & 4 \\
\hline Tasso Jereissati & PSDB & 1 & $\mathrm{CE}$ & n & $\mathrm{s}$ & 1 & 4 \\
\hline Tião Viana & PT & 1 & $A C$ & $\mathrm{~b}$ & s & 3 & 4 \\
\hline Valmir Amaral & PMDB/PTB & 2 & DF & $p$ & n & 3 & 4 \\
\hline Heráclito Fortes & PFL & 2 & $\mathrm{PI}$ & n & s & 4 & 4 \\
\hline
\end{tabular}

Fonte: Elaboração a partir da pesquisa.

Legenda:

\begin{tabular}{|ll|}
\hline Projeto na área social & 1 \\
Projeto na área saúde & 2 \\
Projeto nas duas áreas & 3 \\
Nenhum projeto & 4 \\
\hline & \\
\hline Lei aprovada na área social & 1 \\
Lei aprovada na área saúde & 2 \\
Lei aprovada nas duas áreas & 3 \\
Nenhuma lei aprovada & 4 \\
\hline & \\
\hline É líder partidário & $\mathbf{p}$ \\
É líder do governo & $\mathrm{g}$ \\
É líder de bloco & $\mathrm{b}$ \\
É lider da oposição & $\mathrm{o}$ \\
Não é líder & $\mathrm{n}$ \\
\hline & \\
\hline É titular & $\mathrm{s}$ \\
É suplente & $\mathrm{n}$ \\
\hline
\end{tabular}




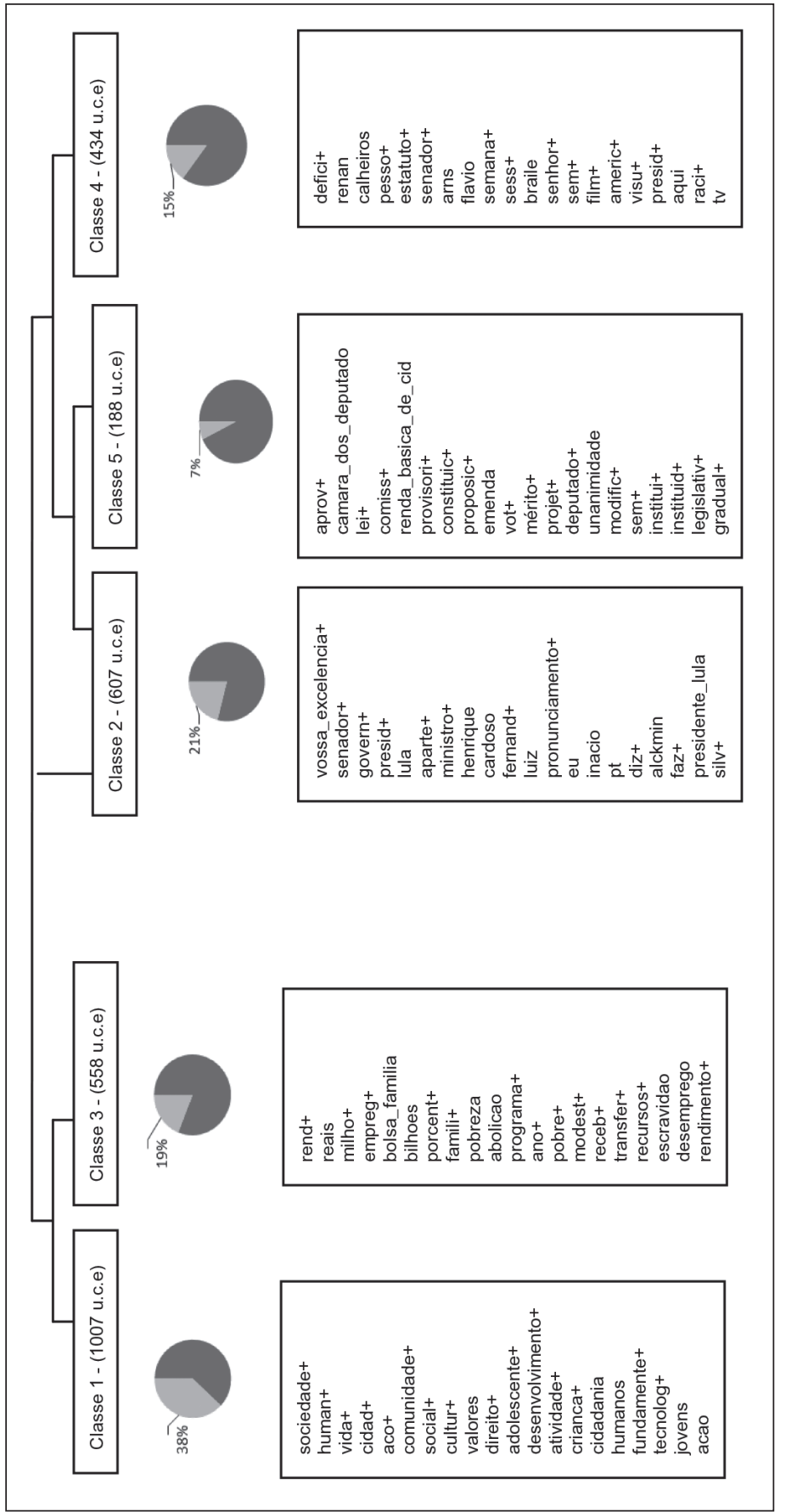

Fonte: Elaboração a partir da pesquisa. 
Para essa pesquisa, um quadro foi formatado a partir dos dados da Análise Alceste, com as presenças significativas da classe 1 que correspondem aos principais "atores sociais" ou "sujeitos típicos" identificados nos discursos desses senadores. Tal análise também nos permitiu compreender quais interlocutores externos ao Senado contribuem para a formação dessa representação de cidadania.

\section{Acerca dos senadores}

Os 46 senadores autores dos 128 discursos analisados pertencem a 11 partidos: PT, PSDB, PMDB, PFL, PSB, PDT, PSOL, PCdoB, PL, PPS, PTB. A distribuição pode ser vista na tabela 1 . Vinte e quatro unidades federativas, de todas as regiōes do Brasil, estão representadas no material de análise. Em termos de quantidade, a Região Norte foi a mais frequente (36 discursos), seguida pela Centro-Oeste (28), Sudeste (26), Sul (24), e por fim, Nordeste (17). Os senadores com maior quantidade de discurso foram: senador Eduardo Suplicy (PT-SP), com 17 discursos, senador Paulo Paim (PT-RS) com 11 discursos, senadores Paulo Octavio (PFL-DF) e Romero Jucá (PMDB-RR) ambos com sete discursos cada um. Os dois primeiros contribuíram, portanto, com 28 discursos no total de 46 do Partido dos Trabalhadores (PT). Esses dois senadores também foram os únicos que aprovaram lei no período de 2003 a 2006, que contemplaram a área social e a área da saúde. Além deles, a senadora Ideli Salvatti (PT-SC) teve lei aprovada na área da saúde.

Tabela 1: Quantidade de discursos por partido

\begin{tabular}{c|c}
\hline PARTIDO & QUANTIDADE \\
\hline PT & 46 \\
\hline PMDB & 23 \\
\hline PSDB & 20 \\
\hline PFL & 12 \\
\hline PDT & 7 \\
\hline PPS & 6 \\
\hline PSB & 4 \\
\hline PSOL & 3 \\
\hline PTB & 3 \\
\hline PCdoB & 2 \\
\hline PL & 2 \\
\hline TOTAL & 128 \\
\hline
\end{tabular}

Fonte: Elaboração a partir da pesquisa. 
As leis aprovadas no período, de autoria desses senadores, foram as seguintes: a Lei n. 10.835, de 08/01/2004, de autoria do senador Eduardo Suplicy, que institui a Renda Básica de Cidadania, e que está no catálogo de Política Social e indexada também com a palavra-chave "saúde"; a Lei n. 11.133, de 14/07/2005, de autoria do senador Paulo Paim, que institui o Dia Nacional de Luta da Pessoa Portadora de Deficiência, catalogada como Política Social; a Lei n. 10.741, de 01/10/2003, do mesmo autor, que dispóe sobre o Estatuto do Idoso, inserida nos catálogos Estatuto e Idoso, e indexada também com a expressão "direito à saúde"; a Lei n. 11.108, de 07/04/2005, de autoria da senadora Ideli Salvatti, que altera a Lei n. 8.080, de 19/09/1990, para garantir as parturientes o direito à presença de acompanhante durante o trabalho de parto, parto e pós-parto imediato, no âmbito do Sistema Único de Saúde (SUS), inserida no catálogo de Saúde Pública. Tal quadro pode ser articulado à conclusão de Amorim Neto e Santos (2003) sobre a atuação de deputados no Congresso Nacional. Eles afirmam que o "paroquialismo" dos deputados não se reflete com frequência nas leis que aprovam e formulam, pois elas expressam conteúdo abrangente, ligadas a questôes nacionais. Há barreiras institucionais importantes que induzem os deputados a concentrar suas atividades legislativas em questóes tópicas de política social de abrangência nacional. Podemos dizer que, no que se refere à atuação dos senadores no período pesquisado, a mesma tendência foi observada.

Duas lideranças do governo, o senador Aloísio Mercadante (PT-SP) e o senador Romero Jucá (PMDB-RR) estiveram presentes, com três e sete discursos, respectivamente. Além disso, apresentaram-se líderes do bloco de apoio ao governo, como a senadora Ideli Salvatti (PT-SC) e o senador Tião Viana (PT-AC), com um discurso cada um. De todos os partidos representados, apenas o Partido Democrático Trabalhista (PDT) não apresentou discurso de sua liderança, mas possui um número alto de discursos, considerando a quantidade de senadores de seu partido no período (7 discursos, e 6 senadores). Isso se deu principalmente à participação do senador Cristovam Buarque (PT-DF / PDT-DF) com quatro discursos. Ele voltou a exercer seu mandato, fazendo oposição ao governo, depois de ter sido ministro e de trocar de partido (do PT para o PDT). A oposição do 
PDT não pode ser igualada a dos partidos de centro-direita, porque, além de não se aliarem ao bloco da oposição, não tiveram seus discursos classificados juntamente com esses partidos. De fato, a classe temática que mais expressa sua posição está bem próxima da classe expressiva do discurso governista, na qual também encontramos u.c.e.s de parlamentares desse partido.

\section{Acerca das classes temáticas}

As cinco classes temáticas da análise Alceste podem ser visualizadas na figura 1, divididas em dois grupos que se interrelacionam. A classe 1 ("Cidadania global e políticas focalizadas”) é a mais significativa, conjugando $38 \%$ das u.c.e.s aproveitadas pelo processamento. Ela foi o ponto de partida para encontrarmos o campo representacional da cidadania. A classe 1 também se aproxima bastante da classe 3 ("Cidadania dos pobres") porque ambas discutem políticas sociais, porém com enfoques diferentes, sendo o conteúdo da última mais voltado às políticas de renda e à pobreza. A classe 4 ("Cidadania dos portadores de deficiências”) também apresenta interação com elas, mas está inserida no grupo 2, provavelmente devido ao conteúdo de moções e comemorações, realizadas no Senado Federal, em função da Semana de Valorização dos Portadores de Deficiência. As classes 5 ("Renda Básica de Cidadania”) e 2 ("A voz da oposição") têm grande proximidade porque têm léxicos semelhantes, que se referem principalmente ao vocabulário institucional dos parlamentares, utilizado para referir-se ao Presidente, aos ministros ou a outros senadores. Mas as duas têm conteúdos diferentes, sendo a classe 2 representativa da oposição ao Governo Lula e ao Programa Fome Zero, enquanto a classe 5 foi formada quase exclusivamente com os discursos do Senador Eduardo Suplicy sobre a proposta da Renda Básica de Cidadania.

O Alceste nos permitiu encontrar "sujeitos típicos", que são os emissores mais representativos de certos temas. A classe 3, por exemplo, pode ser bem representada pela variável que identifica o senador Cristovam Buarque e pela variável de seu partido (PDT). Na classe 1, por outro lado, há senadores de diferentes orientaçōes partidárias, mas o destaque está nas variáveis que indicam 
a presença forte dos líderes do governo e do PMDB, um dos principais partidos da coalizão governista. Além disso, a alta quantidade de u.c.e.s do senador Romero Jucá mostra a pertinência de praticamente todas as u.c.e.s desse senador nesta classe. A classe 2 também possui um sujeito típico, que seria ligado à oposição ao governo. A forte presença da variável do PSDB, e do senador Arthur Virgilio, líder desse partido, mostra isso. Na classe 4, o destaque é do senador Paulo Paim, que reúne outros senadores de diferentes partidos em torno dos estatutos dos quais é propositor. Ele é o responsável por 156 das 219 u.c.e.s da variável que representa o PT. Finalmente, na classe 5, está o senador Eduardo Suplicy, que tem mais da metade de suas u.c.e.s nessa classe.

A grande influência de discursos emitidos por senadores do PMDB e de líderes do governo, na classe mais significativa, pode ser associada ao fato de este ter o partido as características mais claramente ligadas ao presidencialismo de coalizão, como certo fisiologismo, e um estilo catch all, muito influente nos governos estaduais e locais. Portanto, o PMDB é um catalisador importante das ideias que compõem as representaçóes sociais de cidadania entre os senadores, ainda que o Presidente da República tenha sido eleito pelo PT. Os discursos associados ao PT estão mais presentes nas classes 4 ("Cidadania dos portadores de deficiência") e 5 ("Renda básica de cidadania"), devido à alta quantidade de discursos dos senadores Paulo Paim e Eduardo Suplicy. Veremos, porém, que apesar de levantarem temas bem específicos, esses dois sujeitos apresentam noções de políticas sociais ligadas ao elemento unificador da representação social encontrada.

\section{Classe 1: Cidadania global e políticas focalizadas}

A classe 1, apesar de ser a maior em u.c.e.s (38\%), é a que apresenta maior coerência interna, com forte interação entre seus léxicos. É nessa classe em que se encontram as maiores porcentagens das formas reduzidas: cidad+ (cidade, cidades, cidadão, cidadãos, cidadã), sociedade+ (sociedade e sociedades), comunidade+ (comunidade e comunidades), direito+ (direito, direitos), human+ (humano, humanos, humana). Por isso, foi principalmente através dela que chegamos ao campo representacional, ilustrado na figura 2. 


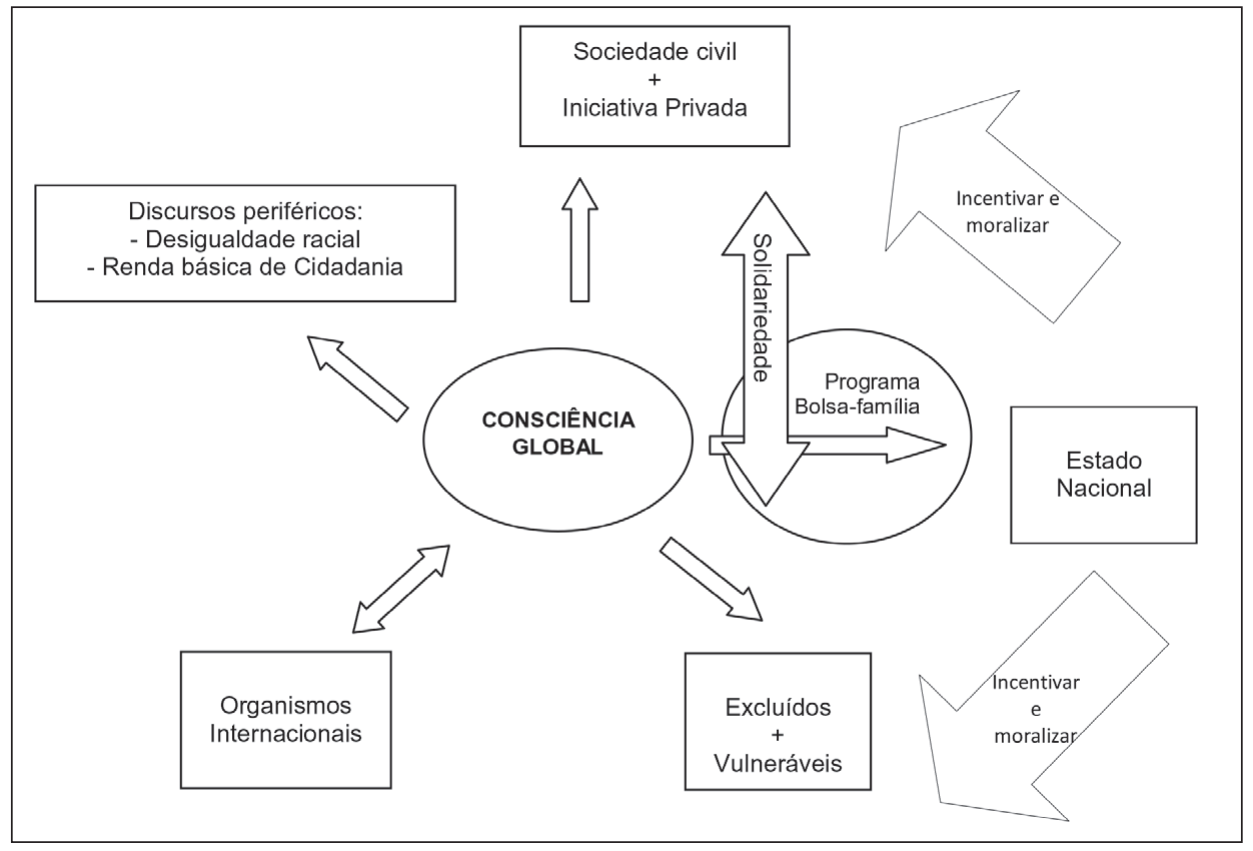

A forma comunidade+ está inserida em falas sobre ações de organizações, empresas e governos (como o Projeto Criança Esperança da Rede Globo, as Organizações Bradesco, os conselhos tutelares, os governos municipais) que promovem algum benefício para comunidades ou para jovens e crianças de determinadas comunidades onde as instituições se localizam. Ou, em alguns casos, refere-se à comunidade como um ator na promoção de melhores condiçôes de vida, de segurança e proteção de suas crianças, adolescentes e idosos. Da mesma forma, sociedade+ aparece tanto como beneficiária como promotora de benefícios para os indivíduos. Os seguintes trechos do corpus ilustram isso:

[...] abrindo espaço político para reconhecer e estabelecer todos os tipos de parcerias com todas as formas de associações comunitárias, reforçando a solidariedade e mobilizando a sociedade para os jogos sociais. (Senador Antonio Carlos Valadares).

[...] seu irreprimível crescimento ocorre por diversos motivos. As organizações do terceiro setor possuem, via de regra, maior proximidade com os destinatários de suas ações, são mais ágeis e flexíveis que as instituiçōes governamentais e possuem aguda consciência acerca do caráter social de sua missão. (Senador Romero Jucá). 
Analisando as u.c.e.s da classe 1, percebemos que nelas são relatados problemas sociais de diferentes setores por uma perspectiva global, ou seja, pela comparação a outros países, pela referência às organizações multilaterais e internacionais, e dados estatísticos. Além disso, a referência aos direitos humanos é muito frequente, não só pelo uso desta expressão, mas pelo uso das categorias "seres humanos" e "humanidade" como justificativas para a garantia de direitos, ou para o merecimento de uma vida melhor, ou ainda para justificar a responsabilidade que cada cidadão deve exercer na resolução dos problemas sociais.

[...] sem solidariedade, nenhuma sociedade pode ser verdadeiramente estável. nao é realista pensar que uns quantos podem continuar a retirar grandes benefícios da globalizacao enquanto milhares de outros permanecem ou são atirados para uma pobreza abjeta. (Senador Cristovam Buarque).

[...] no entanto, o governo deve, sim, patrocinar encontros de todos os setores da sociedade, dos cidadãos que pagam impostos. A luta pelos direitos humanos, pelo reconhecimento à diversidade cultural, étnica e social, significa a convivência com a diferença. (Senador Aloísio Mercadante).

Os atores sociais identificados pelas presenças significativas na classe referemse a diferentes grupos, desde crianças e adolescentes à Organização das Nações Unidas. O Estado, na figura dos governos, é apontado como promotor de espaços nos quais as parcerias devem ser estabelecidas, com a participação de cidadãos independentes, comunidades, empresas, entidades religiosas, instituições públicas e organizações não-governamentais.

Em relação aos direitos e necessidades dos cidadãos, vida+, cultura+ (cultura, culturas, cultural), viol+ (violência e violação), social+ (social, socialista+) e desenvolvimento+ (desenvolvimento, desenvolvimentos) são as formas reduzidas mais características da classe. Especialmente vida+, que tem um qui-quadrado 61 e uma porcentagem de 69\%. Na maioria das u.c.e.s, a palavra está associada às expressōes "qualidade de vida", "condições de vida" e "direito à vida", empregadas em discursos sobre os diferentes temas. $\mathrm{O}$ direito à vida embasa os argumentos ligados aos demais direitos sociais, porém não recebe nenhuma definição específica nos discursos. Poderíamos deduzir que o direito à saúde é um decorrente imediato do direito à vida, mas a palavra "saúde" não é uma presença significativa na classe. Apesar de várias de suas presenças significativas poderem ser interpretadas como elementos da saúde, não se apresentam resultantes de 
políticas ou serviços de saúde, e estão mais associadas a iniciativas e problemas

na área de educação e trabalho, e decorrentes de desigualdade e exclusão social.

\section{Acerca do campo representacional}

A partir da interpretação dos resultados da análise Alceste, foi elaborado o campo representacional (figura 2) com alguns elementos-chave que se interligam na temática "cidadania e a política social". O elemento unificador do campo é a "consciência global". Ela consiste no reconhecimento de um mundo globalizado e em seu papel de referência para a discussão dos problemas sociais e definição das funçôes do Estado e dos cidadãos correspondentes a ele. Assim, é possível destacar elementos emergentes na representação, ligados à consciência global, mas ancorados em aspectos antigos, inseridos nas diferentes formas de cidadania presentes em nossa história política e na literatura. Por essa estrutura abrem-se algumas possibilidades de debates e de visualização de alguns temas, enquanto outros permanecem periféricos ou invisíveis. A renda básica de cidadania e a igualdade racial são temas periféricos, enquanto o programa Bolsa-família articula diferentes atores, pela convocação à solidariedade.

\section{Consciência global e renda básica de cidadania}

O campo representacional encontrado evidencia o discurso adotado no período do governo FHC para a Reforma Administrativa do Estado, que se baseava na constatação de uma crise frente às demandas urgentes da globalização (ALMEIDA, 2007). Tal argumento teve repercussões também entre os senadores durante o período analisado, associado principalmente à defesa dos direitos humanos, ao fenômeno da globalização, e ao que chamamos de "cidadania global".

A cidadania global pode ser definida como proposta substitutiva à soberania da relação dos indivíduos com os Estados-nação diante da constatação da crise dos Estados Nacionais (VIEIRA, 1999). Ela eleva a importância dos benefícios individuais sobre os contratos coletivos. ${ }^{3}$ Se a cidadania contratual é firmada sobre o clássico tripé dos direitos, a cidadania global é pautada pelos direitos humanos, que fazem parte de um discurso mais recente na conjuntura mundial, e são arduamente defendidos por alguns e muito criticados por outros (SCHWARTZMAN, 2004). Eles são associados à retórica individualista, por 
elevar o ser humano, na condição individual, a valor prioritário, atravessando diferenças regionais e culturais que não podem ser ignoradas. Mas a força dessa noção de cidadania pode ser vista nos discursos dos organismos internacionais, ao mesmo tempo em que reverbera nas naçōes, como no Brasil, que criou uma Secretaria Especial de Direitos Humanos, em 1997. Um movimento paradoxal pode ser identificado em diferentes países, quando grupos minoritários se baseiam nos direitos humanos para reivindicar maior inclusão nas políticas públicas nacionais. Tal paradoxo está presente nos discursos analisados e em especial no campo representacional, que sugere uma atuação do governo apenas como regulador nas relações entre indivíduos e instituições, elevando as políticas focalizadas e embaçando a visão de um projeto nacional mais amplo. Isso ilustra a força ideológica do fenômeno da globalização.

A herança institucional que o governo FHC deixou para o governo Lula estava carregada por desenhos de políticas sociais focalizadas, que se ancoram nos discursos globalizados de atenção aos mais pobres, da atuação estatal dirigida ao mercado internacional, e de convocação do terceiro setor para participar efetivamente das ações públicas. Mas as políticas configuradas neste primeiro mandato do Presidente Lula mostram uma tensão com esta herança, sem superála. Elas parecem ancoradas no reconhecimento da globalização, mas esforçandose por centralizar a área social como projeto maior do Estado, o que pode ser relacionado às ideias de tornar a globalização "mais humana" (SANTOS, 2002) e desvincular o trabalho da renda - a chamada renda mínima (BAUMAN, 1999). Porém, de acordo com os discursos dos senadores, a própria integração social deve ser promovida pelo uso provisório da ajuda financeira do Estado para que cada indivíduo tenha autonomia para traçar seus próprios contratos de trabalho e sua participação no mercado de consumo, o que pôde ser observado na intensa discussão acerca das condicionalidades do Programa Bolsa-família.

Santos (2000) aposta na possibilidade de uma globalização na qual o homem passe a ser o valor central. Ou seja, uma pactuação pela vida humana acima do valor do dinheiro. Ele aposta que a forma de solidariedade mantida entre os excluídos do sistema formal de trabalho dê abertura para um "novo equilíbrio" e uma nova forma de fazer política, que coloque a centralidade do social. Ele afirma que "a cultura popular exerce sua qualidade de discurso dos 'de baixo', pondo em relevo o cotidiano dos pobres, das minorias, dos excluídos, por meio 
da exaltação da vida de todos os dias" (SANTOS, 2000, p. 144). Bauman (1999)

sugere a implantação de uma renda mínima para todos os cidadãos, não como compensação para os mais pobres, mas como forma de dissociar renda e trabalho. $\mathrm{O}$ argumento é o de que a renda mínima favorece o exercício da liberdade e da cidadania e a formação de um ciclo benéfico para a sociedade toda, partindo do princípio de que ela é um bem social (BAUMAN, 1999). A proposta da renda mínima foi adotada oficialmente no Brasil, mas associada ao Programa Bolsafamília, o que promoveu a sobreposição da focalização sobre a universalização.

Assim, a "renda básica de cidadania", que é o principal conceito da lei que funda o Programa Bolsa-família, permanece como elemento periférico no esquema da representação social. Ela é periférica porque faz parte desses elementos contraditórios, que estão ligados à consciência global, mas que colocam outro projeto de Estado, embasado em outra noção de cidadania que parece incipiente ou em definição, e que não encontra interlocutores no Senado. Neste período do governo Lula, a renda básica conseguiu entrar na agenda política, principalmente por ter sido vinculada ao Programa Bolsa-família, mas ela não teve um quórum de debate relevante. A referência à globalização impõe grandes desafios à tentativa de promover o fortalecimento do Estado-nação e um padrão de distribuição de riquezas que, de fato, encare o problema estrutural da pobreza. Como podemos observar no seguinte trecho de um discurso do senador Eduardo Suplicy, ela tenta se impor como novo caminho para a cidadania no Brasil inserido numa lógica econômica globalizada:

[...] a Renda de Cidadania será também um símbolo de solidariedade da nação brasileira inserida na economia global. Devido aos seus recursos e à sua posição no mundo, o Brasil tem um imenso potencial para se beneficiar de uma globalização justa [...] Mas nenhum mecanismo de mercado espontâneo irá garantir que esses benefícios atingirão todos os setores e todas as regiōes do país. Alguns estão mesmo fadados a sofrer. Neste contexto, uma renda de cidadania pode ser vista como um dividendo federal. É uma maneira de distribuir para todos os brasileiros, como uma retribuição por um esforço aceito por todos, os ganhos de participação em uma economia globalizada que, de outra forma, tenderia a ser monopolizada por alguns setores e por algumas regiōes. (Senador Eduardo Suplicy).

\section{Solidariedade e desigualdade social}

Outro elemento que exerce função central no campo representacional é a "solidariedade" (presente principalmente nos discursos em prol da cooperação, 
parceria, ações sociais, responsabilidade social entre empresas, instituições e população). Não se trata, porém, de uma solidariedade igualitária, mas de uma próxima às análises de Da Matta (1997), que alimenta um padrão complementar de relações horizontais e verticais, e a convivência de princípios democráticos com uma hierarquia social implícita. A "sociedade" é vista como entidade maior, que engloba diversos atores, dentre eles as comunidades, as famílias, as ONGs, os governos, as empresas e cada cidadão, que devem ser "parceiros" na "luta" contra a desigualdade. $\mathrm{O}$ apelo desses discursos obscurece o debate de temas que se ligam diretamente aos conflitos políticos e sociais do país, impedindo a manifestação de visōes radicais de "lutas de classes". Porém, ainda assim, reconhece-se a exclusão ou a vulnerabilidade de alguns atores sociais que precisam dos cuidados e dos olhares atentos do resto. O grupo dos excluídos e/ou vulneráveis é composto dos pobres (baseado no critério da renda), das crianças, adolescentes e jovens (pobres), dos idosos e portadores de deficiências.

O estudo de Jovchelovitch (2000) sobre as representações da esfera pública no Brasil encontrou um conjunto de representações que definem o espaço público como "terra de ninguém, um espaço sem lei, sem laço social, onde tudo é possível e tudo é permitido" (JOVCHELOVITCH, 2000, p. 103). Tal conjunto resulta num sentimento de ameaça entre os eleitores, que temem a sobreposição do individualismo à coletividade e à identidade pessoal, e por isso evocam a solidariedade dos laços familiares e pessoais como recurso no dia a dia para lidar, inclusive, com questôes do direito e dos deveres de cidadania. Os parlamentares que também participaram de sua pesquisa expressam uma representação que enfatiza um caráter fraco e corrompido do povo brasileiro e dos próprios políticos, separando-os e refletindo-os mutuamente. A autora concluiu que o caráter híbrido do ser brasileiro é o núcleo central dessas representações, pois é nele que reside a fonte da corrupção e ameaça da esfera pública, ao mesmo tempo em que ele é o responsável principal por mudar o país pelo exercício da solidariedade. Em nossa pesquisa, os eleitores aparecem na figura da sociedade, praticamente informe, com alguns pontos críticos - os chamados grupos vulneráveis. E a solidariedade se complementa pela responsabilização de cada cidadão. Portanto, os políticos são figuras fracas, que não têm responsabilidade a mais quanto aos problemas sociais, mesmo sendo representantes políticos de seus eleitores e atores-chave na formulação de políticas públicas. 
A exclusão dos negros e das mulheres é citada apenas como exemplo extraído do passado, com exceção da postura afirmativa do senador Cristovam Buarque (PDT-DF) e da insistência do senador Paulo Paim (PT-RS) em trazer o Estatuto da Igualdade Racial à discussão.

O segundo estatuto, Sr. Presidente, que também está recebendo obstrução, o que também não entendo - e, em relação ao qual o mesmo Senador pediu audiência pública, é o Estatuto da Igualdade Racial, que está em debate há cinco anos no Congresso. [...] Esse estatuto, quando eu estava na Câmara, foi discutido de forma fraternal, organizada, passou na Comissão Especial, mas, infelizmente, está paralisado: na Câmara e no Senado. [...] Não vamos evitar o bom debate. No momento da votação, como se faz aqui no plenário, ou mesmo na Comissão, que se vote contra ou a favor. Faça obstrução, retire o quórum, encaminhe da forma que bem entender, mas não proíba que se discuta a matéria. (Senador Paulo Paim).

A desigualdade racial é, assim, um elemento periférico que se ancora na visão da exclusão e da vulnerabilidade, que demandam por políticas focalizadas, para conseguir aparecer na agenda pública. Tal fato confirma a preponderância de uma noção de "harmonia social" em detrimento do enfrentamento dos conflitos que estão na base da desigualdade social no país. Essa nuance não é nova, mas está presente também nas representações sociais do Brasil analisadas por Arruda (2002) e econtradas por ela na literatura brasileira. Arruda (2002) afirma que os esforços para se estabelecer uma identidade nacional, desde a independência até meados do século $\mathrm{XX}$, foram perpassados pela natureza como paisagem atemporal e paradisíaca, e pela união simbólica das raças, encobrindo assim os conflitos sociais presentes, como a escravidão.

O tom do discurso em torno da mudança, muito presente na campanha eleitoral de Lula em 2002, não ganhou força entre os senadores, mas se associou ao argumento por certa continuidade de um projeto político que está "dando certo" e que garantirá maior "inclusão social", num "mundo globalizado". O sucesso do governo Lula é defendido por seus aliados na unificação e no aumento dos investimentos nos programas sociais já existentes e na manutenção da política econômica do governo anterior. Freitas (2007) argumenta que, na ocasião da posse, Lula tinha apoio social suficiente para tomar medidas difíceis, já previstas no programa do PT, mas não tomou. Para a autora, seu primeiro governo foi extremamente eficiente por ter conseguido fazer reformas e aprovar leis que o governo FHC não conseguiu, e por ter mantido o equilíbrio da dívida pública. Mas também afirma que o mesmo optou por manter intocada a política 
econômica em detrimento de mais investimentos na área social, contribuindo para o enriquecimento do setor bancário.

Por outro lado, o Programa Fome Zero (que pretendia marcar a prioridade da área social) não recebeu ênfase nos discursos dos aliados e é referido como "inexistente" pelos opositores no Senado. Portanto, o material analisado demonstra que, ainda que o Poder Executivo exerça o papel de condutor do debate e das políticas sociais, sua força está no Programa Bolsa-família, por sua capacidade de reunir interesses dos diferentes partidos e atores políticos envolvidos, tanto no Legislativo quanto nos governos locais. As críticas que o programa recebe da oposição dizem respeito apenas à forma de implantação, à fiscalização do ganho do benefício e do cumprimento das contrapartidas pelas famílias. Além disso, como se tornou prioridade para as receitas federais, inclusive do orçamento da Saúde, o programa ampliou muito sua cobertura e aumentou seu apelo eleitoral.

Também podemos destacar que permanece a forte associação entre processo de acumulação e formulação de políticas sociais, no que tange ao que os senadores encaram como problema social e sua possível solução. A conclusão de Santos (1994) sobre a implantação de "uma política voltada para o ideal de equidade que não comprometesse, e se possível ajudasse o esforço de acumulação" (SANTOS, 1994, p. 31), sobre a "cidadania regulada" e as origens de nosso sistema de proteção social, ainda está presente. Porém, a grande diferença está na possibilidade de entrada das demandas de outros grupos sociais, que não são apenas aqueles caracterizados pela "carteira de trabalho". Agora, o processo produtivo é encarado de forma mais abrangente. Ou seja, a globalização e a fase atual do capitalismo mostraram que o mercado consumidor é tão ou mais importante do que a produção de bens para a manutenção do sistema, ampliando o setor de serviços e promovendo áreas recentemente exploradas como vias de "inclusão": a cultura, a informática e os esportes. A autonomia é pregada como objetivo fundamental das políticas, o que está relacionado com discursos de organizações internacionais. Mas aqui ela aparece vinculada à reafirmação da contribuição que o sujeito pode dar à sociedade por sua capacidade de produzir, consumir e ajudar aos outros, fomentando certo ciclo benéfico e harmonioso. Portanto, o discurso pela autonomia está ancorado numa espécie de "utilidade" dos cidadãos para a sociedade, que extrapola a inserção no processo produtivo, mas é fortemente ligada a ela. 
Nos pontos periféricos do campo representacionaléque aparecem poucos elementos para se pensar na cidadania como processo de conquista e luta por direitos. Apesar de ter exercido influência no processo de redemocratização e na Reforma Sanitária, a ideia de uma cidadania em construção não é significativamente presente nos discursos analisados. A Saúde Pública influenciou a entrada de demandas de grupos sociais historicamente excluídos das políticas sociais, mas ela não aparece nos discursos como área própria inserida no debate da proteção. Ao buscarmos os temas discutidos pela subcomissão da saúde e as leis aprovadas no período, por exemplo, percebemos que a pouca atenção com esta área não está só nos discursos, mas também na atuação desses parlamentares. Isso pode ser explicado por duas hipóteses que, devido às limitaçôes do material pesquisado, precisariam ser analisadas em outro momento. Primeiro, a dificuldade em se encarar os conflitos sociais e a preponderância da visão harmônica da sociedade estariam impedindo que uma noção de cidadania como construção social e o ideário da Seguridade Social exercessem ainda mais influência na agenda, produzindo o afastamento da Saúde da discussão sobre os programas sociais em foco. Segundo, uma noção mais ampliada de saúde, incorporando o discurso dos determinantes sociais, estaria convergindo com o foco na diminuição da pobreza e no ganho de autonomia para grupos sociais específicos, deixando para segundo plano a ideia de um sistema universal.

Veloso (2006), em estudo de representações sociais com usuários da saúde pública, encontrou duas dimensões da cidadania em relação com a saúde: uma normativa e outra valorativa, que se articulam. A dimensão valorativa da cidadania é composta por virtudes pessoais ligadas ao bom relacionamento com os outros, pela solidariedade e responsabilidade. A dimensão normativa traz a marca da informação, conhecimento dos direitos e das leis. Ela também encontrou uma característica de "naturalização" da cidadania, como se esta nascesse com cada brasileiro e dissesse sobre o caráter de cada indivíduo. A saúde é representada como bem-estar físico, mas ligada a fatores sociais, como acesso à alimentação, educação, e renda. Ela se relaciona com a cidadania pela capacidade do corpo ser ativo em seu meio social, para que o sujeito estabeleça relações de solidariedade, trabalhe e seja útil. A autonomia é, portanto, um elemento-chave para a relação entre saúde, cidadania e política social, e o forte caráter normativo 
da solidariedade é um de seus meios de promoção. Tanto na pesquisa de Veloso (2006) quanto em nossa pesquisa, a cidadania não se destaca como qualidade de quem possui direitos, mas como responsabilidade de quem é brasileiro. No entanto, o tema da saúde está ancorado na qualidade de vida, que inclui o acesso a direitos sociais.

No estudo de Arruda (2002) sobre as representações sociais relacionadas às eleiçôes presidenciais de 2002 com estudantes de ciências humanas, revelou-se ambiguidade, mas expectativa de mudança na realidade social do país, com a eleição do, então candidato, Lula (FERNANDES et AL., 2003). Pelo método da associação-livre, a palavra "cidadania" aparece associada ao desejo de melhoria na qualidade de vida. É interessante observar que a imagem paradisíaca do Brasil entra em contraste com a presença da pobreza e da corrupção nos discursos, mas contribui para a manutenção de uma esperança para a população no futuro. Isso mostra que as desigualdades sociais têm grande relevância quando o tema "Brasil", "brasileiro" ou "democracia" são evocados. Tal fato pode estar relacionado à pertinência do tema "cidadania e política social" no plenário ao longo do primeiro mandato do governo Lula. A imagem de um grande país em movimento, na direção de melhores condiçôes de vida e de maior visibilidade no mundo, está presente, mas também permanece o "Brasil paradisíaco", no qual não se enxergam as lutas de classes.

Assim, podemos dizer que as representações sociais ligadas à esfera pública no Brasil estão em processo de mudança, ancoradas na peculiar associação da hierarquia social com as ideias modernas de direitos civis, políticos e sociais, e dos princípios de igualdade e liberdade. Mas estão incorporando novas referências de identidade social e territorial. A representação social de cidadania apresentada tem duas faces complementares e paradoxais: por um lado, amplia as possibilidades de participação dos eleitores e de grupos historicamente excluídos na esfera pública; por outro, casa-se com um projeto de Estado que não combate efetivamente a desigualdade entre os cidadãos e dificulta a implantação de projetos políticos que pretendam superá-la. Estamos, assim, vivendo um processo de reorganização da representação social de cidadania, em franco movimento, que permite ainda a entrada de elementos contraditórios, a fim de modificá-la. Para que tal mudança ocorra em direção a uma cidadania igualitária, é necessário levar em conta 
especialmente a força dos projetos de solidariedade, da visão centrada na pobreza,

dos determinantes sociais da saúde e do fenômeno da globalização.

\section{Considerações finais}

A interpretação dos resultados propiciou o encontro de relativo consenso quanto à ideia-chave de cidadania entre os senadores. Ou seja, os dados foram coerentes com uma das características peculiares de nosso sistema político, que se refere à pouca consistência ideológica dos partidos reforçada pelo presidencialismo de coalizão. Os discursos mostram que o conflito político mais evidente não se dá em torno de projetos de cidadania e desenvolvimento social diferentes para o país, mas à reivindicação da autoria dos programas sociais, com vistas à manutenção ou alternância do poder. Além disso, não houve debates relevantes sobre as leis de autoria desses senadores aprovadas, apenas discursos isolados ou moções de homenagens a essas leis. A maior parte das falas aborda temas abrangentes, sem intenção de encaminhar alguma contribuição à política ou projeto de lei específicos.

Tal quadro corrobora o que outros autores já afirmaram acerca da dinâmica entre Executivo e Legislativo no Brasil (CINTRA, 2004; FIGUEIREDO, 2001; PALERMO, 2000; ABRANCHES, 1988), configurada a partir de negociações com as coligações. Ela torna a posição individual dos parlamentares geralmente pouco significante e, portanto, seus discursos no plenário detêm pouca influência decisória. Por outro lado, os discursos podem revelar o contexto mais amplo de sua atuação, por carregar toda a influência dos projetos do governo e do histórico de preponderância do Executivo.

Assim, concluímos que a aplicação de um método de análise lexical em uma grande quantidade de discursos para analisar uma representação social no Poder Legislativo é muito positiva, tendo em vista que, além de trazer à tona diferentes temas importantes para o sistema político e mostrar suas inter-relações, produz novas questóes para serem exploradas em outros estudos. Além disso, o estudo possibilitou uma compreensão abrangente do debate sobre cidadania articulada ao contexto político-institucional e às diretrizes governamentais do período, sendo este um movimento fundamental para avançarmos na análise de políticas públicas no Brasil, em especial nas políticas setoriais como de saúde. ${ }^{4}$ 


\section{Referências}

ABRANCHES, S.H. Presidencialismo de coalizão: o dilema institucional brasileiro. Revista Dados. Rio de Janeiro, v.31, n.1, p.5-34, 1998.

ALBA, M. El método ALCESTE y su aplicación ao estudio de las representaciones sociales del espacio urbano: el caso de la Ciudad de Mexico. Papers on Social Representations, v.13, p.1.1-1.20, 2004.

ALMEIDA, M.H.T. O Estado no Brasil Contemporâneo. Um passeio pela história. In: MELO, C.R.; SÁEZ, M.A. (Orgs.). A democracia brasileira. Balanço e perspectivas para o século XXI. Belo Horizonte: EdUFMG, 2007, p.17-31.

AMORIM NETO, O.; SANTOS, F. O segredo ineficiente revisto: o que propóem e o que aprovam os deputados brasileiros. Revista Dados. Rio de Janeiro, v.46, n.4, p.661-698, 2003. ARRUDA, A. O ambiente natural e os habitantes no imaginário brasileiro: negociando a diferença. In: (Org.). Representando a alteridade. Petrópolis: Vozes, 2002, p.17-46.

BAUMAN, Z. Globalização: as conseqüências humanas. Rio de Janeiro: Jorge Zahar, 1999. BERGER, P.L.; LUCKMANN, T. A construção social da realidade. Petrópolis: Vozes, 2007. BRASIL. Constituição Federal (1988). 5ª Ed. São Paulo: Ed. RT, 1988.

CASTEL, R. As metamorfoses da questão social: uma crônica do salário. Petrópolis: Vozes, 1999. CINTRA, A.O. O sistema de governo no Brasil. In AVELAR, L.; CINTRA, A.O. (Orgs.). $O$ sistema politico brasileiro: uma introdução. Rio de Janeiro: Fundação Konrad AdenauerStiftung, 2004, p.59-79.

DA MATTA, R. Carnavais, malandros e heróis. Para uma sociologia do dilema brasileiro. Rio de Janeiro: Rocco, 1997.

DRAIBE, S.M. Avaliação de implementação: esboço de uma metodologia de trabalho em políticas públicas. In BANDEIRA, M.C.; CARVALHO, M.C.B. (Orgs.). Tendências e perspectivas na avaliação de politicas e programas sociais. São Paulo: IEE/PUC, 2001.

FERNANDES, F.S. et al. Eleiçôes e os candidatos à presidência da república do Brasil em 2002: Explorando a representação social de estudantes de Ciências Humanas na região metropolitana do Rio de Janeiro. In: JORNADA INTERNACIONAL, 3; CONFERENCIA BRASILEIRA SOBRE REPRESENTAÇÕES SOCIAIS, 1., Rio de Janeiro. Textos completos... Rio de Janeiro: UERJ, p. 1515-1532, 2003.

FIGUEIREDO, A. Instituições e política no controle do Executivo. Revista Dados. Rio de Janeiro, v.44, n.4, p.689-727, 2001.

FREITAS, R. de C.M. O governo Lula e a proteção social no Brasil: desafios e perspectivas Rev. Katál. Florianópolis, v.10, n.1 p.65-74, 2007.

GOULART, F. Políticas e instituições de saúde: o vivido, o percebido e o representado. Dissertação (Mestrado em Saúde Pública) - Escola Nacional de Saúde Pública, Fundação Oswaldo Cruz, Rio de Janeiro, 1992. 
HOCHMAN, G.; ARRETCHE, M.; MARQUES, E. Introdução. In: . (Orgs.)

Políticas públicas no Brasil. Rio de Janeiro: Fiocruz, 2007, p. 13-26.

JOVCHELOVITCH, S. Representações sociais e esfera pública: a construção simbólica dos espaços públicos no Brasil. Petrópolis: Vozes, 2000.

MOSCOVICI, S. A representação social da psicanálise: resultados da pesquisa de opiniāo e análise teórica. Rio de Janeiro: Zahar, 1978.

. Representações sociais: investigações em Psicologia Social. Petrópolis: Vozes, 2003.

PALERMO, V. Como se governa o Brasil? O debate sobre as instituições políticas e a gestão de governo. Revista Dados. Rio de Janeiro, v.43, n.3, 2000.

SANTOS, W.G. Cidadania e justiça: a política social na ordem brasileira. $3^{\mathrm{a}}$ Ed. Rio de Janeiro: Campus, 1994.

SANTOS, M. Por uma outra globalização: do pensamento único à consciência universal. Petrópolis:, Vozes, 2000.

SANTOS, W. G. Roteiro bibliográfico do pensamento político-social brasileiro (1870-1965). Belo Horizonte: EdUFMG, 2002.

SISTEMA DE INFORMAÇÃO DO CONGRESSO NACIONAL. Disponível em: <http:// www6.Senado.gov.br/sicon/PreparaPesquisaAvancada.action> Acesso em: mar-dez 2008.

SCHWARTZMAN, S. As causas da pobreza. Rio de Janeiro: FGV, 2004.

VELOSO, R. Representaçôes sociais da cidadania e seus nexos com a saúde e o cuidado de enfermagem. Dissertação (Mestrado em Enfermagem) - Faculdade de Enfermagem, Universidade Federal do Rio de Janeiro, Rio de Janeiro, 2006.

VIEIRA, L. Cidadania global e Estado Nacional. Revista Dados. Rio de Janeiro, v.42,n.3, p.395-419, 1999.

\section{Notas}

${ }^{1}$ Comparando-se a quantidade de discursos entre 2003 e 2006, na base do SICON, com o filtro para os assuntos "cidadania" e "política social", com a quantidade total existente na base de dados até o ano de 2006 (inclusive), ele nos informa que de 1952 a 2006 há um total de 225 discursos catalogados. Portanto, os anos de 2003 a 2006 representam mais da metade desses discursos na base.

${ }^{2}$ Vale ressaltar que as políticas sociais desenvolvidas nos governos de Fernando Henrique Cardoso e Lula são também expressão de movimentos políticos prévios, bem como resultados de pactos estabelecidos na Constituição Federal de 1988, que ampliou o conceito de proteção social e a responsabilidade do Estado. ${ }^{3}$ A sociedade salarial é estruturada pelo contrato de trabalho coletivo, portanto, o coletivo é neste caso um ator social central, marcando a socialização em certos países como a França (CASTEL, 1999).

${ }^{4}$ C.F Pombo-de-Barros participou na elaboração da concepção do artigo, análise preliminar e redação do manuscrito. T.W.F. Baptista participou na elaboração da concepção do artigo, discussão da análise e redação do manuscrito. A.M.S. Arruda participou na elaboração da concepção do artigo, discussão da análise e redação do manuscrito. 


\section{There is life in social politics: social representation of citizenship among Brazilian senators}

The paper discusses the results of a survey on the social representations of citizenship found in speeches issued by senators in the Senate, between years 2003 and 2006. The analyzed material includes speeches of 46 senators, the theme of social politics, and was investigated using the Alceste software. And despite different political parties are represented, we find relative consensus on the key idea of citizenship. The representational field showed the centrality of global awareness and input peripherals issues in political debates, such as the Basic Income and Racial Equality, and also signaled little influence on health sector issues raised by senators, in social politics, in period studied.

> Key words: social representations; citizenship; Senate; social politics. 